\title{
Words matter: how to increase gender and LGBTQIA + inclusivity at Biological Invasions
}

\author{
Deah Lieurance $(\mathbb{D} \cdot$ Sara Kuebbing $(\mathbb{D} \cdot$ Matthew A. McCary $(\mathbb{D} \cdot$ Martin A. Nuñez
}

Received: 4 October 2021 / Accepted: 17 October 2021 / Published online: 17 November 2021

(C) The Author(s), under exclusive licence to Springer Nature Switzerland AG 2021

Academic journals set guidelines for article submissions and the review process including paper length, word counts, text formats, and resolution of figures, but they do not always provide specific messaging about how to do this with inclusivity. A more inclusive climate in academic publishing will more broadly advance scientific knowledge because it will ensure no voices are absent from the process (Nielsen et al. 2018). We are writing this editorial after conversations related to gathering the demographic data of current and past Biological Invasions editors (Kuebbing et al.

D. Lieurance $(\bowtie)$

Agronomy Department, University of Florida,

Gainesville, FL 32611, USA

e-mail: dmlieurance@ufl.edu

S. Kuebbing

Department of Biological Sciences, University of

Pittsburgh, Pittsburgh, PA 15260, USA

M. A. McCary

Department of BioSciences, Rice University, Houston, TX 77005, USA

M. A. Nuñez

Grupo de Ecología de Invasiones, INIBIOMA,

CONICET, Universidad Nacional del Comahue, Quintral 1250, 8400 San Carlos de Bariloche, CP, Argentina

M. A. Nuñez

Department of Biology and Biochemistry, University of Houston, Houston, TX 77204, USA
2021). We identify two policies that could reduce disparities and increase inclusivity in academic publishing for authors, reviewers, and editors: develop and adopt procedures to make it easier for authors to amend their names retroactively on publications after gender transitioning, taking a partner's last name, or for religious reasons (Hunt 2020; Tanenbaum et al. 2020), and provide guidance for using gender-neutral language in submission and editorial communications.

Efforts to be inclusive to transgender, non-binary, and gender-diverse (henceforth shortened to "trans") authors must address the need to correct the names on their prior work. These corrections serve not only trans authors but also address name changes for other reasons such as religion or those who change their surname. Trans authors have described the process as "navigating a confusing and exhausting landscape of ad-hoc name changes, refusals, delays, and closed doors" (Tanenbaum, 2021b). The benefits of a simplified and comprehensive name-change policy are two-fold. First, updating names in the publication record offers a practical solution to connecting publications by the same author who published under different names. Second, this process signals inclusivity by acknowledging the harmful impact of deadnaming on trans authors and respecting their right to decide what names are public and what names should no longer be associated with their work. Deadnaming is the practice of using a trans person's 
birth name after it has been replaced by their chosen name as part of their transition. It can be accidental or intentional, and it invalidates a person's identity and dehumanizes a trans person's experience. Further, maintaining a deadname in the public record draws unwanted attention to a trans author's name and can lead to discrimination, misgendering, and harassment. Currently, trans authors often shoulder the burden of a laborious, expensive, and time-consuming process where each publisher is contacted, and the author must persuade the publishers to agree to the change (Tanenbaum et al. 2021a).

In 2021, the Committee of Publication Ethics (COPE), whose core mission is to educate and support editors and publishers and to provide guidance on achieving ethical practices in the publishing culture (https://publicationethics.org), published a list of five guiding principles and best practices for processing name changes in publishing: (1) accessibility-make name changes available to authors upon request without legal documentation and other barriers to the author, (2) comprehensiveness-removal of all occurrences of an author's previous name from the record, (3) invisibility - changes should not draw attention to the gender identity of an author, (4) expediency and efficiency — changes should be made in a timely manner and reduce the burden on the publisher to correct the record, and (5) recurrence and maintenance-publishers should regularly audit the record and make corrections as needed to prevent the dissemination of incorrect information (Tanenbaum et al., 2021a). Some publishers are currently moving towards policies that allow efficient and discreet name changes, including Elsevier, Wiley, the American Association for the Advancement of Science, and Springer Nature (DePaul 2021).

In June 2021, Springer Nature launched its new, inclusive author name-change policy to enable trans authors to update their names on the version of record and associated metadata retroactively in all Springer Nature journals, books, and conference proceedings (Springer Nature Group 2021). This policy strives to address many of the principles outlined by COPE for name changes, including comprehensiveness, invisibility, and expediency and efficiency. Additionally, these changes will include updating biographical information, such as pronouns and author photographs. This will help make authors feel secure and supported while also ensuring they receive full recognition of their work. Additionally, Springer Nature encourages authors also to establish and use ORCID IDs, which can also facilitate linking an author's work in a persistent and gender-free way (https://orcid.org). We look forward to the implementation of these policies at Biological Invasions.

Perhaps the simplest recommendation for improving inclusivity in the publication process is adopting gender-neutral language throughout the submission, editing, and review process. Frequently, both individuals and groups are referred to using male pronouns. In academic publishing, women and trans authors, reviewers, and editors are often misgendered in publishing communications (e.g., submission and decision letters). There is an easy fix for this. Using gender-neutral and other bias-free language can reduce gender bias, promote inclusivity, and improve the academic publishing climate. Bragagnolo (2021) outlined steps to achieve unbiased, gender-neutral language in academic writing specific to manuscript preparation, but these actions can be employed at all levels of peer review. These tips include avoiding the use of 'man' to refer to all people (e.g., humans, people, humankind), using job titles that are free from gender stereotyping (e.g., mail carrier vs. mailman), and avoiding the use of 'he/his' pronouns when referring to a group of people (Bragagnolo 2021). Bragaganolo also suggests replacing gendered pronouns (she/her/hers and he/him/his) with genderneutral pronouns (they/them/theirs). Gender-neutral pronouns are appropriate when a person has not shared their gender identity. We encourage this language change and suggest that editors and reviewers use terms such as "the author", the corresponding author's surname, or Dr. (where appropriate) when writing reviews or letters. Editorial leadership at Biological Invasions is starting the process of amending submission guidelines to include using gender-neutral language (Table 1) and a short statement regarding language in letters inviting reviewers. Additionally, this guidance will also be provided to new and existing members of the editorial board. Adopting genderneutral language at Biological Invasions and other ecological journals would be a small but meaningful step on the road to inclusivity. 
Table 1 List of some gender-neutral suggestions to use during the submission, editing, and review process in publishing (Bragagnolo 2021; UNC Writing Center 2021)

\begin{tabular}{|c|c|}
\hline Gendered language & Gender-neutral language \\
\hline \multicolumn{2}{|l|}{ Use gender neutral pronouns } \\
\hline 'he' and 'his' & 'he or she' or 'his or her' \\
\hline 'he' and 'she' & 'they' \\
\hline 'him' and 'her' & 'them' \\
\hline 'his' and 'hers' & 'theirs' \\
\hline \multicolumn{2}{|l|}{ Use plural pronouns and adjectives } \\
\hline $\begin{array}{l}\text { A reviewer should use gender-neutral language in his } \\
\text { communications }\end{array}$ & $\begin{array}{l}\text { Reviewers should use gender-neutral language in their } \\
\text { communications }\end{array}$ \\
\hline \multicolumn{2}{|l|}{ Use the relative pronoun "who' } \\
\hline $\begin{array}{l}\text { If the author is not satisfied with the Editor's decision, he should } \\
\text { request a second review }\end{array}$ & $\begin{array}{l}\text { An author who is not satisfied with an editorial decision can } \\
\text { request a second review }\end{array}$ \\
\hline \multicolumn{2}{|l|}{ Omit gendered words entirely } \\
\hline The author should justify why he choose that method & The author should justify the methods \\
\hline \multicolumn{2}{|l|}{ Use gender-neutral nouns } \\
\hline Man & 'person', 'individual' \\
\hline Mankind & $\begin{array}{l}\text { 'humans', 'persons', 'humankind', 'human beings', 'people', } \\
\text { etc }\end{array}$ \\
\hline Freshman & 'first-year student' \\
\hline Man-made & 'artificial, 'human-made', 'machine-made', 'synthetic' \\
\hline \multicolumn{2}{|l|}{ Use appropriate titles and names } \\
\hline Miss and Mrs & Ms. (does not suggest marital status) \\
\hline Sir & $\begin{array}{l}\text { 'Dear Editor', 'Dear Members of the Search Committee', 'To } \\
\text { Whom it May Concern' }\end{array}$ \\
\hline
\end{tabular}

\section{Declarations}

Conflict of interest The author declares there is no conflict of interest.

Consent to participate All authors consent to participate in this manuscript.

Consent for publication All authors consent in publishing this manuscript.

\section{References}

Bragagnolo C (2021) Editing Tip: Writing in Gender-Neutral Language. AJE Scholar https://www.aje.com/arc/writinggender-neutral-language/ accessed 2 Aug 2021

Committee of Publication Ethics (2021) About COPE. Committee of Publication Ethics https://publicationethics.org/ about/our-organisation accessed 14 Sept 2021

DePaul A (2021) Scientific publishers expedite name changes for authors. Nature. https://doi.org/10.1038/d41586-02102014-7
Hunt L (2020) For academic publishing to be trans-inclusive, authors must be allowed to retroactively change their names. Impact of Social Sciences Blog. London School of Economics http://eprints.lse.ac.uk/id/eprint/106846 accessed 2 Aug 2021

Kuebbing S, McCary MA, Lieurance D, Nuñez MA, Chiuffo MC, Zhang B, Seebens H, Simberloff D, Meyerson LA (2021) A self-study of editorial board diversity at Biological Invasions. Biological Invasions XX:XX

Nielsen MW, Bloch CW, Schiebinger L (2018) Making gender diversity work for scientific discovery and innovation. Nat Hum Behav 2:726-734

Springer Nature Group (2021) Springer Nature introduces trans inclusive name change policy. Springer Nature Group. https://group.springernature.com/gp/group/media/pressreleases/springer-nature-introduces-trans-inclusive-namechange-policy/19305714 accessed 16 Sept 2021

Tanenbaum TJ (2020) Publishers: let transgender scholars correct their names. Nature 583:493-494

Tanenbaum TJ, Rettig I, Schwartz HM, Watson BM, Goetz TG, Spiel K, Hill M (2021a) A vision for a more trans-inclusive publishing world: guest article. Committee of Publication Ethics https://publicationethics.org/news/vision-moretrans-inclusive-publishing-world accessed 14 Sept 2021 
Tanenbaum TJ (2021b) Publishers: Changing the names of trans people in their own work is not enough. Sage Perspectives. https://perspectivesblog.sagepub.com/blog/authorservices/publishers-changing-the-names-of-trans-peoplein-their-own-work-is-not-enough accessed 2 Aug 2021

UNC Writing Center (2021) Gender-inclusive language. University of North Carolina https://writingcenter.unc.edu/ tips-and-tools/gender-inclusive-language/ accessed 23 Sept, 2021

Publisher's Note Springer Nature remains neutral with regard to jurisdictional claims in published maps and institutional affiliations. 